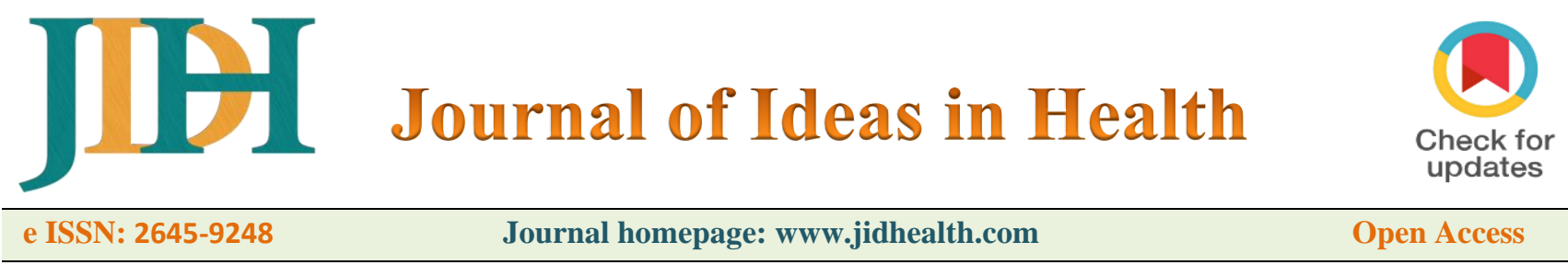

Viewpoint Article

\title{
Monsoon vicissitude in COVID-19 and the vulnerable Indian health care system: an urgent call to circumvent the impending doom
}

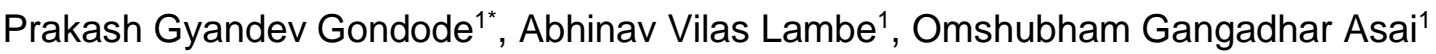

\begin{abstract}
With the escalating number of covid-19 positive cases and amidst the glooming shadows of an anticipated second wave of the covid-19 pandemic, the health care system of a developing country like India is already under pressure. With the encroachment of monsoon season, the ghosts of the past haunt India. Monsoon brings along endemic diseases like dengue, malaria, swine flu, Japanese encephalitis, chikungunya, etc. Every year there is significant morbidity and mortality. These diseases have clinical features of fever, sore throat, and body aches in common, which also happens to be the common manifestations of covid-19. The growing stigma related to COVID-19, the fake news, and fear related to hospitalization and isolation may lead to low reporting cases to the hospitals. Lockdown and nonavailability of beds may perplex the situation further. There is an urgent need of the hour to address this grave issue to prevent a major mishappening. A comprehensive evaluation of the health-care systems is desperately needed, especially on the fronts of governance, decision making, scientific and technical advice, and operational capacity.
\end{abstract}

Keywords: COVID-19, Dengue, Endemic Diseases, Malaria, Monsoon, India

\section{Background}

India is now only behind the USA in COVID-19 cases globally. As of 04 December 2020, there have been 9,571780 confirmed cases of COVID-19 with 139,227 deaths [1]. India is already struggling to tackle the steep rise in daily COVID-19 cases, exhausting its health care resources. Being a developing country, it still has many limitations in health care services. It ranks 57 th in the Global Health Security index. There is a substantial disparity in subnational levels in the Health care access index [2].

While the dark clouds of the COVID-19 pandemic are still hovering over the Indian health care system, monsoon and the endemic illnesses are knocking on doors. Every year illnesses like Dengue, swine flu, chikungunya, and malaria consume and exhaust India's health care resources during monsoon. It goes to such an extreme that there are bed-sharing in many hospitals due to unavailability of bed. The gravity of the concern cannot be eluded. According to the data by the Indian government, in 2019, there have been a total of 338494 cases and 77 deaths by malaria, 157315 cases and 166 deaths by dengue, 28798 cases

*Correspondence: drprakash777@gmail.com

${ }^{1}$ Department of Anesthesiology, All India Institute of Medical Sciences, Nagpur, Maharashtra, India.

Full list of author information is available at the end of the article and 1218 deaths by swine flu, 2545 cases and 266 deaths by Japanese encephalitis, 81914 suspected and 12205 confirmed cases of chikungunya [3,4]. The picture gets even scarier as both COVID-19 and these diseases share similar initial symptoms like fever, myalgia, weakness. This may masquerade either way. Fever, dry cough, and tiredness are the common symptoms of COVID-19 as per WHO. Other fewer common symptoms are body ache, sore throat, headache, nasal congestion, conjunctivitis, diarrhea, loss of smell or taste, skin rash, or finger discoloration. Typically, malaria produces fever, headache, vomiting, and other flu-like symptoms. Dengue has an abrupt onset of high fever, headache, retro-orbital pain, joint and muscle pains, loss of sense of taste and appetite. Chikungunya usually starts suddenly with fever, chills, headache, nausea, vomiting, rash, and joint pain [3].

COVID-19 has changed the scenario completely this year. There is a very real possibility that an individual experiencing a febrile episode may not get optimum medical care in time. The majority of Indians use public transport. With lockdown implied in many areas of the country, it is not easy to reach hospitals. There is limited/no vacancy for many non-COVID-19 patients as many hospitals are pre-occupied with COVID-19 cases. The scariest issue is social stigma. People are afraid that once they are declared COVID-19 positive [5], discrimination in society, friends \& relatives, and residential areas is an unavoidable consequence. India has already witnessed cases 
where a pregnant woman was reportedly abandoned by her family when she found COVID-19 positive. COVID-19 survivors in India were stalked and bullied on social media. Even doctors and health care workers faced grave social exclusion; some were asked to evacuate the rented homes and were even threatened [6].

Now is the time not to shy away from but to align investments for improving access and quality across the full array of health-care needs. India has to address and overcome the deficiencies in public health functions, financing, health, and social workforce, health information systems, access to diagnosis and treatment, and the role of scientific research. A comprehensive evaluation of the health-care systems is desperately needed, especially on the fronts of governance, decision making, scientific and technical advice, and operational capacity.

Urgent actions that need to be taken; -

- Compiling and Displaying the list of non-COVID-19 hospitals on various media platforms, including social media.

- Safeguard and promote access to non-COVID-19 hospitals with a safe and affordable commute.

- Invest in improving the present conditions with quality infrastructure for non-COVID-19 facilities.

- Re-activate and scale-up services for the early recognition and management of child wasting, acute febrile illness, and various water bore and vector-borne diseases endemic to India, along with COVID-19 testing centers.

- Reinforce and design effective programs and social movements to reduce the stigma and encourage people to seek medical care, thus curtailing the pandemic.

- Reaching out and educating the rural population, the illiterates, and underprivileged communities.

- Empowering primary health care services.

- Sustain the delivery of nutritious \& safe meals for vulnerable communities and children to fight malnutrition and upsurge community protection to preserve access to essential services and nutritious diets.

- Minimizing the gap in health care quality in urban \& rural belts as there is an urgent need to improve access to and quality of health care across service areas and for all populations.

\section{Abbreviation}

COVID-19: Corona Virus Disease; WHO: World Health Organization

Declaration

Acknowledgement

None

Funding

The authors received no financial support for their research, authorship, and/or publication of this article.

Availability of data and materials

Data will be available by emailing drprakash777@gmail.com

\section{Authors' contributions}

Authors were equally involved in all parts of the manuscript (Viewpoint) drafting, concept, design, writing, reviewing, editing, and approving the manuscript in its final form. Authors have read and approved the final manuscript.

Ethics approval and consent to participate

We conducted the research following the Declaration of Helsinki. However, Viewpoint Articles need no ethics committee approval.

Consent for publication

Not applicable

Competing interest

The author declare that they have no competing interests.

\section{Open Access}

This article is distributed under the terms of the Creative Commons $\begin{array}{llll}\text { Attribution } & 4.0 & \text { International License }\end{array}$ (http://creativecommons.org/licenses/by/4.0/), which permits unrestricted use, distribution, and reproduction in any medium, provided you give appropriate credit to the original author(s) and the source, provide a link to the Creative Commons license, and indicate if changes were made. The Creative Commons Public Domain Dedication waiver (http://creativecommons.org/publicdomain/zero/1.0/) applies to the data made available in this article, unless otherwise stated.

Author details

${ }^{1}$ Department of Anesthesiology, All India Institute of Medical Sciences, Nagpur, Maharashtra, India.

\section{Article Info}

Received: 28 October 2020

Accepted: 05 December 2020

Published: 20 December 2020

\section{References}

1. World Health Organisation. Global- India. Available from: https://covid19.who.int/region/searo/country/in. [ Accessed on 04 December 2020].

2. Fullman N, Yearwood J, Abay SM, Abbafati C, Abd-Allah F, Abdela J, et al. Measuring performance on the Healthcare Access and Quality Index for 195 countries and territories and selected subnational locations: a systematic analysis from the Global Burden of Disease Study 2016. The Lancet. 2018 Jun 2;391(10136):2236-71. https://doi.org/10.1016/S01406736(18)32281-5.

3. National Vector Borne Disease Control Programme. Directorate General of Health Services. Ministry of Health \& Family Welfare, Government of India. Available from: https://nvbdcp.gov.in/index4.php?lang=1\&level=0\&linkid=407\&1 $\mathrm{id}=3683$. [ Accessed on 04 December 2020].

4. National Centre for Disease Control. Directorate General of Health Services. Ministry of Health \& Family Welfare, Government of India. Available from: https://ncdc.gov.in/index4.php?lang=1\&level=0\&linkid=119\&lid =276. [ Accessed on 04 December 2020].

5. Desai MZ, Khan AR, Kulkarni R, Hegde B. The psychological impact of COVID-19 and the subsequent social isolation on the general population of Karnataka, India. Journal of Ideas in Health. 2020 Sep 23;3(Special1):190-5. https://doi.org/10.47108/jidhealth.Vol3.IssSpecial1.51.

6. Bagcchi S. Stigma during the COVID-19 pandemic. The Lancet. Infectious Diseases. $2020 \quad$ Jul;20(7):782. https://doi.org/10.1016/S1473-3099(20)30498-9. 